Original Research Article

\title{
Change from baseline as an outcome illustrates escape behaviour of rats in hot plate method
}

\author{
Rama Mohan Pathapati, Manchi Rajesh Kumar, B. L. Kudagi, Madhavulu Buchineni*
}

Department of Pharmacology, Narayana Medical College, Nellore, Andhra Pradesh, India

Received: 09 September 2017

Accepted: 16 September 2017

\section{*Correspondence to:}

Dr. Madhavulu Buchineni, Email: madhavulu@gmail.com

Copyright: (C) the author(s), publisher and licensee Medip Academy. This is an openaccess article distributed under the terms of the Creative Commons Attribution NonCommercial License, which permits unrestricted noncommercial use, distribution, and reproduction in any medium, provided the original work is properly cited.

\begin{abstract}
Background: The Hot Plate test is a thermal hyperalgesia model to assess the analgesic activity of many compounds. Traditional analysis compares reaction times with controls, reports only analgesic activity without considering escape reflex. Escape reflex to pain sensation also provides an indirect measure of analgesic activity. However, it requires repeated exposure of rats to hot plate. We explored the learning activities and escape behaviour of rats by calculating the change from baseline of reaction times.

Methods: Male Wister strain albino rats, weighing between 150-200mg were used for assessment of hot-plate induced hyperalgesia. Author analysed the analgesic activity of aspirin $(100 \mathrm{mg} / \mathrm{Kg})$ and compared with animals receiving saline. Aspirin and saline were administered $1 \mathrm{hr}$ orally before the commencement of the experiment. The reaction time was recorded at every $30 \mathrm{~min}$ up to $6 \mathrm{hrs}$.

Results: With traditional analysis, we can observe that the onset of action, peak action and duration of analgesic activity of aspirin was at 0.5, 2.0 and 5.0 hours respectively. Peak inhibition of reaction time was seen at 2 hours with a magnitude of $474 \%$. When we applied a statistical procedure, absolute change from baseline statistics, we found that animals treated with aspirin also exhibited escape reflex after fading of drug response and animals treated with saline demonstrated early $(0.5 \mathrm{hr})$ escape behaviour from the hot plate and continued throughout the rest of the experiment.

Conclusions: Change from baseline as an outcome illustrates escape behaviour of rats in hot plate method and it should be employed along with percentage inhibition during assessment of analgesic activity.
\end{abstract}

Keywords: Analgesic activity, Change from baseline, Escape reflex, Hot plate, Percentage inhibition

\section{INTRODUCTION}

The hot plate test is a supraspinally organised response to noxious thermal stimulus in animals. ${ }^{1,2}$ It is a behavioural model of nociception, where the animals escape from the hot plate following a noxious thermal stimulus. Licking is a rapid response and a direct indicator of the nociceptive threshold. Whereas escaping is an in-depth response, with a latency, and has an emotional component of escaping. ${ }^{3}$ Hot plate nociception is commonly used to verify for acute CNS analgesia; this test is selective in detecting the analgesic action of morphine like drugs. ${ }^{4}$ However, they fail to yield significant results for the analgesia caused by non-steroidal anti-inflammatory drugs.

Traditionally analgesic activity of a test compound is reported as a percentage increase of reaction time in comparison with the baseline scores of controls group. This analysis does not consider baseline score in of the test group and does not account for baseline variations in reaction times between two groups. One of the reasons for not taking baseline reading in the trial group is that the rats might learn escape response to the hot plate setting. ${ }^{5}$

In this present study, we explore whether baseline readings will affect the anti-nociceptive data of aspirin by using 
Eddy's hot plate induced hyperalgesia model and compared with control. Additionally, we have used a repeated measures design to evaluate whether the escape behavior calculated by change from baseline can be used as indirect marker of analgesic effect.

\section{METHODS}

This Study was originally designed to assess the analgesic activity of natural compounds in our department. Male Wister strain albino rats, weighing between 150-200mg were used for assessment of hot-plate induced hyperalgesia. ${ }^{2}$ Institutional ethics committee for animal safety approved this study protocol. We only analysed the analgesic activity of aspirin $(100 \mathrm{mg} / \mathrm{Kg})$ and compared with animals receiving saline. Each group consisted of six animals. Drugs were administered $1 \mathrm{hr}$ orally before the commencement of the experiment, the temperature of the hot plate was set at $56 \pm 1^{\circ} \mathrm{C}$, with the help of thermostat. Animals were placed on the hot plate with the paws touching the plate only for $15 \mathrm{sec}$ to prevent the injury to the animal. The reaction time was recorded at every $30 \mathrm{~min}$ up to 6 hrs.

We calculated the percentage inhibition in the reaction time an index of analgesic activity by using the formula (100 X $\mathrm{RT}_{\mathrm{a}}-\mathrm{RT}_{\mathrm{s} /} \mathrm{RT}_{\mathrm{s}}$ ) Where ' $\mathrm{RT}_{\mathrm{s}}$ ' represents reaction times of saline at a time point and ' $R T_{a}$ ' represents reaction time of test drugs at a time point. Additionally, we also calculated the absolute change from baseline to illustrate escape behaviour of rats to a thermal stimulus.

\section{Statistical analysis}

Data were described as mean, absolute numbers and percentages. Statistical analysis was performed using Microsoft Excel-2007 and graphs were drawn using Sigma Graph pad prism version-4 USA.

\section{RESULTS}

It was observed that the onset of action, peak action and duration of analgesic activity of aspirin was at 0.5, 2.0 and 5.0 hours respectively (Table 1). Peak inhibition of reaction time was seen at 2 hours with a magnitude of $474 \%$. Theoretically, it is well known that animal's exhibits avoidance reflex/ escape behaviour to repeated exposure to the thermal stimulus. However, analysis of Table 1 does not show this effect.

The duration of action of aspirin is 5.0 hours (Table 1), however after application of change from baseline- the duration of action of aspirin was 4.0 hours instead of 5.0 (Table 2). Escape behaviour can be appreciated by observing the negative values in absolute change. Escape behaviour of rats treated with aspirin was noticed after fading of drug response at $4 \mathrm{hrs}$. This reaction seems to be a hyperalgesia rebound effect. Animals treated with saline demonstrated early escape behaviour $(0.5 \mathrm{hr})$ from the hot plate and continued throughout the rest of the experiment.

\section{DISCUSSION}

Hot plate is the widely used animal model in identifying novel analgesics. The pain reaction time of a test compound is compared to a baseline taken from the controls. It was explored the learning activities and escape behaviour of rats on repeated exposure to hot plate by calculating the change from baseline of reaction times.

In the study, it was found that the maximum analgesic activity of aspirin is $474 \%$. We also noticed the baseline variation between two groups was $58 \%$. It can be concluded that any effect below this threshold cannot be counted for the analgesic activity of aspirin.

Many of the studies report the analgesic activity of the drug as percentage inhibition/increase in reaction times. Such an interpretation is an easily understandable way to the researchers, who are not statisticians.

Table 1: Traditional analysis showing analgesic activity of aspirin on repeated measures.

\begin{tabular}{|lllll|}
\hline $\begin{array}{l}\text { Time } \\
(\mathbf{h r})\end{array}$ & $\begin{array}{l}\text { Reaction Time } \\
\text { Aspirin }(\mathbf{S})\end{array}$ & $\begin{array}{l}\text { Reaction Time } \\
\text { Saline }(\mathbf{S})\end{array}$ & $\begin{array}{l}\text { \% Inhibition Formula } \\
\mathbf{1 0 0} *\left(\mathbf{R T}_{\mathrm{a}}-\mathbf{R T}_{\mathrm{s}}\right) / \mathbf{R T}_{\mathrm{s}}\end{array}$ & \begin{tabular}{c} 
\% Inhibition \\
\hline 0
\end{tabular} \\
\hline 0.5 & 1.58 & 1.38 & $100 *(1.58-1.38) / 1.38$ & $58.00 \%$ \\
\hline 1 & 4.56 & 1.34 & $100 *(4.56-1.34) / 1.34$ & $356.00 \%$ \\
\hline 1.5 & 5.14 & 1.32 & $100 *(5.14-1.32) / 1.32$ & $414.00 \%$ \\
\hline 2 & 5.68 & 1.27 & $100 *(5.68-1.27) / 1.27$ & $468.00 \%$ \\
\hline 2.5 & 5.74 & 1.26 & $100 *(5.74-1.26) / 1.26$ & $474.00 \%$ \\
\hline 3 & 4.25 & 1.28 & $100 *(4.25-1.28) / 1.28$ & $325.00 \%$ \\
\hline 3.5 & 3.23 & 1.27 & $100 *(3.23-1.27) / 1.27$ & $223.00 \%$ \\
\hline 4 & 2.71 & 1.24 & $100 *(2.71-1.24) / 1.24$ & $171.00 \%$ \\
\hline 4.5 & 2.32 & 1.19 & $100 *(2.32-1.19) / 1.19$ & $132.00 \%$ \\
\hline 5 & 1.99 & 1.2 & $100 *(1.99-1.20) / 1.20$ & $99.00 \%$ \\
\hline 5.5 & 1.64 & 1.18 & $100 *(1.64-1.18) / 1.18$ & $64.00 \%$ \\
\hline 6 & 1.45 & 1.14 & $100 *(1.45-1.14) / 1.14$ & $45.00 \%$ \\
\hline
\end{tabular}


Table 2: Absolute change from baseline showing escape reflex in rats.

\begin{tabular}{|c|c|c|c|c|c|}
\hline \multirow{2}{*}{$\begin{array}{l}\text { Time } \\
\text { (hours) }\end{array}$} & \multicolumn{2}{|c|}{ Reaction Time (S) } & \multicolumn{3}{|c|}{ Absolute Change from Baseline in Reaction Times (S) } \\
\hline & Aspirin & Saline & Formula* & Aspirin & Saline \\
\hline 0 & 1.58 & 1.38 & - & - & - \\
\hline 0.5 & 4.56 & 1.34 & $\mathrm{RT}{ }_{(0.5 \mathrm{Hr})}-\mathrm{RT} \mathrm{(}_{(0 \mathrm{Hr}) \text { aspirin }}$ & 1.98 & -0.04 \\
\hline 1 & 5.14 & 1.32 & $\mathrm{RT}_{(1.0 \mathrm{Hr})}-\mathrm{RT}_{(\mathrm{OHr})}$ aspirin & 2.56 & -0.05 \\
\hline 1.5 & 5.68 & 1.27 & $\mathrm{RT}_{(1.5 \mathrm{Hr})}-\mathrm{RT}(\mathrm{OHr})$ aspirin & 3.10 & -0.06 \\
\hline 2 & 5.74 & 1.26 & $\mathrm{RT}_{(2.0 \mathrm{Hr})}-\mathrm{RT}_{(\mathrm{OHr})}$ aspirin & 3.16 & -0.12 \\
\hline 2.5 & 4.25 & 1.28 & $\mathrm{RT}_{(2.5 \mathrm{Hr})}-\mathrm{RT} \mathrm{T}_{(0 \mathrm{Hr}) \text { aspirin }}$ & 1.67 & -0.10 \\
\hline 3 & 3.23 & 1.27 & $\mathrm{RT}_{(3 . \mathrm{OHr})}-\mathrm{RT}{ }_{(\mathrm{OHr})}$ aspirin & 0.65 & -0.11 \\
\hline 3.5 & 2.71 & 1.24 & $\mathrm{RT}_{(3.5 \mathrm{Hr})}-\mathrm{RT}_{(\mathrm{OHr})}$ aspirin & 0.13 & -0.14 \\
\hline 4 & 2.32 & 1.19 & $\mathrm{RT}_{(4.0 \mathrm{Hr})}-\mathrm{RT}_{(\mathrm{OHr})}$ aspirin & -0.27 & -0.19 \\
\hline 4.5 & 1.99 & 1.2 & $\mathrm{RT}_{(4.5 \mathrm{Hr})}-\mathrm{RT}$ (0Hr) aspirin & -0.60 & -0.18 \\
\hline 5 & 1.64 & 1.18 & $\mathrm{RT}_{(5 . \mathrm{OHr})}-\mathrm{RT}_{(\mathrm{OHr})}$ aspirin & -0.94 & -0.20 \\
\hline 5.5 & 1.45 & 1.14 & $\mathrm{RT}_{(5.5 \mathrm{Hr})}-\mathrm{RT} \mathrm{T}_{(0 \mathrm{Hr}) \text { aspirin }}$ & -1.13 & -0.24 \\
\hline 6 & 1.33 & 1.12 & $\mathrm{RT}_{(6.0 \mathrm{Hr})}-\mathrm{RT}{ }_{(\mathrm{OHr})}$ aspirin & -1.25 & -0.26 \\
\hline
\end{tabular}

From the researcher point of view the drug effects would be better evaluated in single tests rather than repeated measures. ${ }^{6}$ From a statistical perspective, the percentage change is independent of the unit of measurement and is the only advantages. ${ }^{7}$ On the contrary, the percentage change is a ratio of two variables, its distribution is uncertain, and the standard deviation of percentage change has no stable relationship with the baseline score. ${ }^{8}$ Furthermore, such a type of analysis may not characterise the escaping behaviour of the animal which is an indirect measure of drug activity. The passive avoidance task is a fear-aggravated test used to evaluate learning and memory in rodent models of CNS disorders. ${ }^{9,10}$

We explored the learning activities and escape behaviour after repeated exposure to hot plate experimentation by employing a statistical procedure called the change from baseline. To systemically illustrate the escape behaviour (jumping off) of the animal, the reaction times at various time points were subtracted from the group baseline reaction times. We showed that animals treated even with aspirin also exhibit escape behaviour after fading of drug response and animals treated with saline demonstrated early escape behaviour from the hot plate and continued throughout the rest of the experiment. The avoidance reflex shown by the animals treated with aspirin seems to be a hyperalgesic rebound effect. Escape reflex provides a unique method for measuring the relationship between the affective/motivational and sensory dimensions of pain processing. ${ }^{11,12}$ One study had shown that only escaping behaviour would be preserved when the animal was repeatedly exposed to hot plate experimentation, while another study reported that, modifications in avoidance reactions occur on repeated exposure to the hot plate. ${ }^{13}$ These modifications could be linked to procedural memory when animals were exposed to various amnesia- inducing treatments. ${ }^{14}$ One more study, says that escape behaviour as a quantitative measure of nociception which works well for morphine on the hot plate but not with NSAIDs. ${ }^{5}$

Many randomised pain studies measure a continuous outcome at baseline and several times after treatment using a design called repeated measures. They use an absolute change of outcome at two points, among them one being baseline. Change from baseline has adequate power when the correlations between baseline and post-treatment scores are high and will create a bias towards the group with poorer baseline scores. ${ }^{15,16}$

Most of the time, the choice of statistical analysis depends more on the research work and the researcher's own experience. However, while choosing any method, consider baseline variations since variations in reaction times at baseline are as high as $58 \%$.

\section{CONCLUSION}

In a repeated measures design, change from the baseline analysis acts as a complement to the percentage inhibition which is used to report anti-nociceptive activity on hot plate method.

\section{Funding: No funding sources}

Conflict of interest: None declared

Ethical approval: The study was approved by the Institutional Animal Ethics Committee

\section{REFERENCES}

1. Eddy NB, Leimbach D. Synthetic analgesics. II. Dithienylbutenyl-and dithienylbutylamines. Journal of 
Pharmacology and Experimental Therapeutics. 1953;107(3):385-93.

2. Matsumiya LC, Sorge RE, Sotocinal SG, Tabaka JM, Wieskopf JS, Zaloum A, et al. Using the Mouse Grimace Scale to reevaluate the efficacy of postoperative analgesics in laboratory mice. Journal of the american association for laboratory animal science. 2012;51(1):42-9.

3. Espejo EF, Mir D. Structure of the rat's behaviour in the hot plate test. Behavioural brain research. 1993;56(2):171-6.

4. LaBuda CJ, Fuchs PN. Low dose aspirin attenuates escape/avoidance behavior, but does not reduce mechanical hyperalgesia in a rodent model of inflammatory pain. Neuroscience letters. 2001;304(3):137-40.

5. Koch K. Assessing the impact of non-steroidal antiinflammatory drugs in the hot plate test: An alternative model. 2006.

6. Espejo EF, Stinus L, Cador M, Mir D. Effects of morphine and naloxone on behaviour in the hot plate test: an ethopharmacological study in the rat. Psychopharmacology. 1994 Jan;113(3-4):500-10. PubMed PMID: 7862866. Epub 1994/01/01. eng.

7. Törnqvist L, Vartia P, Vartia YO. How should relative changes be measured? The American Statistician. 1985;39(1):43-6.

8. Vickers AJ. The use of percentage change from baseline as an outcome in a controlled trial is statistically inefficient: a simulation study. BMC Medical Research Methodology. 2001 June 28;1(1):6.

9. Kruk-Slomka M, Boguszewska-Czubara A, Slomka T, Budzynska B, Biala G. Correlations between the Memory-Related Behavior and the Level of Oxidative
Stress Biomarkers in the Mice Brain, Provoked by an Acute Administration of CB Receptor Ligands. Neural Plasticity. 2016;2016:15.

10. Passive Avoidance Task Behavioural and Functional sScience Laboratory. Stanford Medical. Available at: http://med.stanford.edu/sbfnl/services $/ \mathrm{bm} / \mathrm{lm} / \mathrm{bml}$ passive.html.

11. Fuchs PN. Beyond reflexive measures to examine higher order pain processing in rats. Pain Research and Management. 2000;5(3):215-9.

12. Mauderli AP, Acosta-Rua A, Vierck CJ. An operant assay of thermal pain in conscious, unrestrained rats. Journal of neuroscience methods. 2000;97(1):19-29.

13. Sonika G, Manubala R, Deepak J. Comparative studies on anti-inflammatory activity of Coriandrum Sativum, Datura stramonium and Azadirachta Indica. Asian J Exp Biol Sci. 2010;1(1):151-4.

14. Suaudeau C, do-Rego JC, Costentin J. Modifications in avoidance reactions of mice, on a second exposure to the hot plate, resist to various amnesia-inducing treatments. Cognitive Brain Research. 2005;25(1):339-47.

15. Zhang L, Han K. How to Analyze Change from Baseline: Absolute or Percentage Change; 2009.

16. Kaiser L. Adjusting for baseline: change or percentage change? Statistics in medicine. 1989;8(10):1183-90.

Cite this article as: Pathapati RM, Kumar MR, Kudagi BL, Buchineni M. Change from baseline as an outcome illustrates escape behaviour of rats in hot plate method. Int $\mathbf{J}$ Basic Clin Pharmacol 2017;6:2348-51. 